\title{
IDENTIFICATION AND CHARACTERIZATION OF DIVERSE XYLANASES FROM THERMOPHILIC AND THERMOTOLERANT FUNGI
}

\author{
Sonia K. Ghatora, ${ }^{a}$ Bhupinder S. Chadha, ${ }^{a *}$ A. K. Badhan ${ }^{a}$, H. S. Saini, ${ }^{a}$ and M. K. Bhat ${ }^{b}$ \\ Thirteen fungal isolates included in this study expressed multiple xylanase \\ isoforms as observed by xylan zymograms of polyacrylamide gel electrophoresis \\ (PAGE) and isoelectrofocussing (IEF) fractionated proteins. Eighty-three \\ xylanases produced by these thermophilic and thermotolerant strains were \\ detected using the IEF profiling technique. Xylanases identified on the basis of \\ their isoelectric points ( $\mathrm{pl}$ ) were functionally diverse and exhibited differential \\ catalytic activities against various xylan types (birch wood xylan, larch wood \\ xylan, oat spelt xylan, rye arabino xylan and wheat arabino xylan) as well as \\ debranched arabinan. Thermophilic isolates, Chaetomium thermophilum, \\ Humicola insolens, Melanocarpus sp., Malbranchea sp. and Thermoascus \\ aurantiacus, were found to produce alkaline active xylanases that showed a \\ bleach boosting effect on Decker pulp resulting in increased brightness (1.60- \\ 2.04 ISO units).
}

Keywords: Thermophilic and Thermotolerant fungi, Multiple xylanases, PAGE and IEF fractionated proteins, Specificities and catalytic activities, Alkaline active xylanases.

Contact information: a: Department of Microbiology, Guru Nanak Dev University, Amritsar-143005, INDIA; b: Food Materials Science Division, Institute of Food Research, Norwich Research Park, Colney, Norwich, NR4 7UA, UK.

*Corresponding Author: chadhabs@yahoo.com

\section{INTRODUCTION}

Xylan, the major hemicellulosic constituent of hardwood and softwood, is a branched heteropolysaccharide constituting a backbone of $\beta-1,4$ linked xylopyranosyl units substituted with arabinosyl, glucuronyl and acetyl residues (Shallom and Shoham 2003). The structure of xylan components from different sources depends upon extraction procedures as well as the frequency, number and type of substitutions (Viikari et al. 1994; Saha 2003). The hydrolysis of the xylan backbone is accomplished by endoxylanases (EC 3.2.1.8) and $\beta$-xylosidases (EC 3.2.1.37) along with a variety of debranching enzymes, i.e. $\alpha$-L-arabinofuranosidases, $\alpha$-glucuronidases and acetyl esterases (Collins et al. 2005). Many of the xylanase-producing microorganisms express multiple isoforms (Wong et al. 1988) that have been ascribed to a variety of reasons, i.e., heterogeneity and complexity of xylan structure, genetic redundancy and post-translational modifications, etc. (Kormelink and Voragnen 1993; Li et al. 2000).

Thermophilic fungi, a unique group of microorganisms, that thrive at high temperatures are often associated with piles of agricultural and forestry products and other composting materials (Maheshwari et al. 2000). The distribution and colonization of thermophilic fungal population in compost is closely related to their ability to produce a variety of cell wall degrading enzymes (Sharma 1989). Since these fungal strains function in amelioration of xylan substrate present in lignocellulosic waste, each xylanase 
produced may be biotechnologically important and show specialized function. There is need to isolate and identify such novel xylanases from diverse indigenous strains. Some of the thermophilic fungi, Chaetomium thermophile, Humicola insolens (syn. Scytalidium thermophilum), Thermomyces lanuginosus and Thermoascus aurantiacus have been reported to produce biotechnologically-important, thermostable xylanases. These xylanases are used in a variety of applications, i.e., clarification of juice and wine, starch separation and production of functional food ingredients, improving the quality of bakery products and in animal feed biotechnology (Saha 2003). Xylanases showing transglycosylation activities can also be used for tailoring drugs and in the preparation of neoglycoproteins (Eneyaskaya et al. 2003). Alkaline-active xylanases of thermophilic fungi find application in bleaching of pulp in paper industry obviating the need for chlorine (to some extent) in ecofriendly process (Subramanium and Prema 2002).

Due to their huge potential, xylanases with novel properties must be isolated and identified. This study highlights the identification and characterization of multiple and catalytically diverse xylanases produced by thermophilic and thermotolerant fungi isolated from composting soils, and their application in pulp bleaching.

\section{MATERIALS AND METHODS}

\section{Microorganisms and Culture Conditions}

Diverse thermophilic and thermotolerant fungi, namely, Absidia corymbifera MTCC 4620, Acrophialophora nainiana Edward MTCC 6662, Aspergillus caespitosus MTCC 6326, Aspergillus terreus MTCC 6335, Chaetomium thermophilum MTCC 4981, Chrysosporium lucknowense MTCC 3921, Emericella nidulans var. lata MTCC 6327, Humicola insolens MTCC 4520, Humicola fuscoatra MTCC 6329, Melanocarpus sp. MTCC 3922, Malbranchea sp. MTCC 4887, Penicillium lagena MTCC 6334 and Thermoascus aurantiacus MTCC 4890 were isolated from composting soils and grown and maintained on yeast-starch agar (YpSs, $\mathrm{pH} 7.0)$ of following composition $(\% \mathrm{w} / \mathrm{v})$ : starch 1.5, yeast extract $0.4, \mathrm{~K}_{2} \mathrm{HPO}_{4} 0.23, \mathrm{KH}_{2} \mathrm{PO}_{4} 0.2, \mathrm{MgSO}_{4} .7 \mathrm{H}_{2} \mathrm{O} 0.05$, citric acid 0.057 and agar 2.0 (Cooney and Emerson 1964). The fungi were cultured at $45-50{ }^{\circ} \mathrm{C}$ for 7-10 days and stored at $4{ }^{\circ} \mathrm{C}$. These indigenous fungal strains were identified as described

by Cooney and Emerson (1964) and have been deposited with Microbial Type Culture Collection (IMTECH, Chandigarh, India).

\section{Enzyme Production}

The cultures were grown in $250 \mathrm{ml}$ Erlenmeyer flasks that contained $50 \mathrm{ml}$ of production medium of the following composition $(\% \mathrm{w} / \mathrm{v})$ : corn cobs 2.0 ; oat spelt xylan 0.1 , yeast extract $1.0, \mathrm{KH}_{2} \mathrm{PO}_{4} 0.3, \mathrm{CaCl}_{2}, 0.05, \mathrm{MgSO}_{4} 0.05$ and $1 \% \mathrm{v} / \mathrm{v}$ of trace element solution that contained (\% w/v): $\left(\mathrm{NH}_{4}\right)_{2} \mathrm{SO}_{4} 0.2, \mathrm{KCl} 0.5, \mathrm{CaCl}_{2} 0.1, \mathrm{MgSO}_{4} 0.5, \mathrm{ZnSO}_{4}$ 0.01 and $\mathrm{CuSO}_{4} 0.005$. The $\mathrm{pH}$ of the medium was adjusted to 6.0 prior to sterilization. The flasks were inoculated with 2 agar discs ( $2 \mathrm{~mm}$ in diameter) of 7-10 days old culture from YpSs agar plates and were incubated under shaking conditions (120 rpm) at 45/50 ${ }^{\circ} \mathrm{C}$ up to 10 days (experiments performed in triplicates). The crude enzymes were filtered and centrifuged $(11000 \mathrm{x} \mathrm{g})$ for $10 \mathrm{~min}$. The xylanase activity was estimated in these filtrates. 
The xylanase assay of crude filtrate was determined using birch wood xylan as the substrate. The assay mixture which contained $500 \mu \mathrm{l}$ of $1 \%$ birch wood xylan (Sigma, X0502) prepared in $50 \mathrm{mM} \mathrm{Na-citrate} \mathrm{buffer} \mathrm{with} \mathrm{pH} 6.5$ and $500 \mu$ l suitably diluted enzyme was incubated at $50{ }^{\circ} \mathrm{C}$ for 5 minutes. The reaction was stopped by the addition of $3 \mathrm{ml}$ dinitrosalicylic acid (DNS) reagent and the contents were boiled for 15 minutes. The developed color was read at $540 \mathrm{~nm}$ using Novaspec II spectrophotometer (Pharmacia). The amount of reducing sugar liberated was quantified using the xylose standard. Xylanase activity is expressed in terms of units per $\mathrm{ml}$ of xylanase solution. A unit of activity is defined as the micromoles of xylose released per minute under assay conditions (Gomez de Segura et al. 1998; Sunna and Berguist 2003).

EGTA-EDTA mix (each @ $1 \mathrm{mM}$ ) and PMSF (2 mM) were added to the filtrate $0.02 \%$ sodium azide in order to avoid contamination and inhibit protease activity. Further, the clear supernatants were desalted using a PD-10 column (Pharmacia) and lyophilized (HETO, Drywinner 3) and the concentrated samples were used for fractionation on PAGE and IEF.

\section{Electrophoresis and Iso-Electric Focusing}

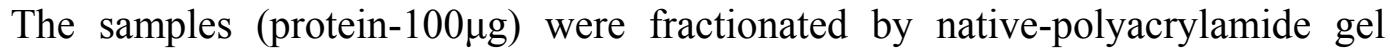
electrophoresis (PAGE) that was performed in 7.5\% gel with 4\% stacking gel using the Mini-Protean II system of Biorad by the method of Laemmli (1970). Similarly, isoelectric-focusing (IEF) using $5 \%$ acrylamide gel containing $2.4 \%$ broad $\mathrm{pH}$ range (3.510.0) ampholine carrier ampholyte (Amersham Biosciences) was performed (MiniProtean II system, BIORAD). Ethanolamine $(0.4 \% \mathrm{v} / \mathrm{v})$ and sulphuric acid $(0.2 \% \mathrm{v} / \mathrm{v})$ were used as cathodic and anodic electrolyte solutions, respectively (Bhat and Wood 1989). Isoelectrofocusing was carried out for $1 \mathrm{~h}$ each at a constant voltage of $100 \mathrm{~V}$ and $200 \mathrm{~V}$ followed by $500 \mathrm{~V}$ for $30 \mathrm{~min}$.

\section{Activity Staining}

Xylanase activity in PAGE and IEF gels was detected by activity staining (Zymogram technique) with 1\% agarose replica containing covalently dyed RBB-Xylan prepared from oat spelt xylan (SIGMA). Upon completion of electrophoresis, the gels were incubated in sodium acetate buffer $(50 \mathrm{mM}, \mathrm{pH} 6.0)$ for $30 \mathrm{~min}$ and then overlaid on RBB-Xylan containing gel for $30-60 \mathrm{~min}$ at $50{ }^{\circ} \mathrm{C}$. In order to avoid band diffusion, these gels were dried at $60{ }^{\circ} \mathrm{C}$.

\section{Quantification of Xylanases}

After fractionating the proteins on IEF, the gel in each lane was sliced $(1.25 \mathrm{~mm}$ thickness). Each slice was incubated in $500 \mu$ l sodium citrate buffer $(50 \mathrm{mM}, \mathrm{pH}$ 6.0) for $72 \mathrm{~h}$ at $4{ }^{\circ} \mathrm{C}$. The eluted protein in each fraction was assayed for xylanase activity against $1 \%$ birch wood xylan.

\section{Substrate Specificity and Activity of Xylanase at Alkaline pH}

The xylanase active fractions identified against birch wood xylan were also assayed for their catalytic action against different xylan types (oat spelt xylan, larch wood xylan, rye arabino xylan, wheat arabino xylan) and debranched arabinan. In order to 
identify alkaline active xylanases, the assay under alkaline conditions using Tris- $\mathrm{HCl}$ buffer (50 mM, pH 9.0) was performed against birch wood xylan.

\section{Bleaching of Pulp}

Decker pulp (10\% w/w), provided by ABC paper mills (Hoshiarpur, India), was subjected to alkaline extraction $(\mathrm{NaOH}, 6.3 \% \mathrm{w} / \mathrm{v})$ for $30 \mathrm{~min}$. at $50{ }^{\circ} \mathrm{C}$, then was thoroughly washed with water and dried. A slurry of alkali treated pulp $(6 \% \mathrm{w} / \mathrm{v}$ pulp consistency) prepared in phosphate buffer $(0.1 \mathrm{M}, \mathrm{pH} 7.0)$ was treated with 10 units xylanase/g (dry weight) at $65{ }^{\circ} \mathrm{C}$ for $120 \mathrm{~min}$ under mild shaking (60 rpm). No enzyme was added in the control. A post-alkaline extraction $(\mathrm{NaOH}, 2 \% \mathrm{w} / \mathrm{v} ; 6 \% \mathrm{w} / \mathrm{v}$ pulp consistency) was performed at $55{ }^{\circ} \mathrm{C}$ under mild shaking (60 rpm).

The enzyme-mediated release of chromophoric material from pulp was measured spectrophotometrically at 237, 254, 280 and $465 \mathrm{~nm}$ in the enzyme filtrates after a $2 \mathrm{~h}$ incubation period using UV-VIS spectrophotometer (Shimadzu, UV mini 1240). Reducing sugars released from pulp were measured over the same incubation period according to the dinitrosalicylic acid method. The hand-sheets of bleached pulp were prepared according to standard TAPPI method (T 205 om-88) and their brightness was determined with an Elrepho 070 (Lorentzen and Wettre, Sweden).

\section{RESULTS AND DISCUSSION}

\section{Production and Multiplicity of Xylanases}

The fungal strains included in this study produced xylanases to a varied extent, where thermophilic fungal strains expressed high levels of xylanases as compared to thermotolerant fungi (Table 1). High xylanase titres produced by thermophilic fungi that are prevalent in composting soils possibly accelerate the process of natural decomposition. Melanocarpus sp. produced 264.2 units $\mathrm{ml}^{-1}$ of xylanases followed by Che. thermophilum and Malbranchea sp. (162.2 and 141.7 units $\mathrm{ml}^{-1}$ ), respectively. Among thermotolerant fungal strains, maximum xylanase production was observed with A. terreus (38.0 units $\left.\mathrm{ml}^{-1}\right)$ followed by P. lagena (32.4 units $\left.\mathrm{ml}^{-1}\right)$ and E. nidulans var. lata (31.2 units $\left.\mathrm{ml}^{-1}\right)$.

The analysis of crude enzymes produced by these fungal cultures revealed the presence of multiple xylanases. Even though multiplicity of xylanases is widespread in microorganisms, it has been demonstrated in few fungi including Trichoderma sp., Sclerotium rolfsii and Aspergillus sp. (Wong et al. 1988; Sachslehner et al. 1998; de Vries and Visser 2001), the thermophilic fungi, Melanocarpus albomyces IIS 68 and Myceliophthora sp. (Saraswat and Bisaria 2000; Badhan et al. 2004), and in an anaerobic fungal strain, Neocallimastix frontalis (Gomez de Segura et al. 1998). Studies revealing functionally diverse multiple isoforms of xylanases from thermophilic fungi isolated from the same ecosystem have not been reported earlier. Thirteen fungal cultures isolated (in this study) from composting soils produced 51 diverse xylanases identified based on their electrophoretic mobilities using PAGE zymograms (Fig. 1-A). Both A. terreus and E. nidulans var. lata produced seven xylanase isoforms with very high to low electrophoretic mobilities. Whereas, Ac. nainiana, Che. thermophilum, H. fuscoatra and T. aurantiacus produced two xylanases each with distinct banding pattern. Furthermore, 
the resolution of filtrates on IEF gels showed 65 xylanases with distinct pI. E. nidulans var. lata, $H$. fuscoatra and $H$. insolens produced xylanases of highly basic to acidic pI 9.7-3.4 with a high degree of multiplicity (Fig. 1-B). The production of a wide variety of xylanases by thermophilic and thermotolerant fungi isolated from composting soils suggests that these xylanases possibly exhibit overlapping yet dissimilar specificities to achieve superior xylan hydrolysis (Wong et al. 1988). Studies on xylanases from Myceliophthora $\mathrm{sp}$. from our laboratory have clearly shown that the multiplicity was not a result of proteolytic post-translational modification (Badhan et al. 2006). Multiple xylanases may be the product of different alleles of the same gene (allozymes) or distinct gene products produced by a fungus to enhance the utilization of xylan (Wong et al. 1988; Uffen 1997).
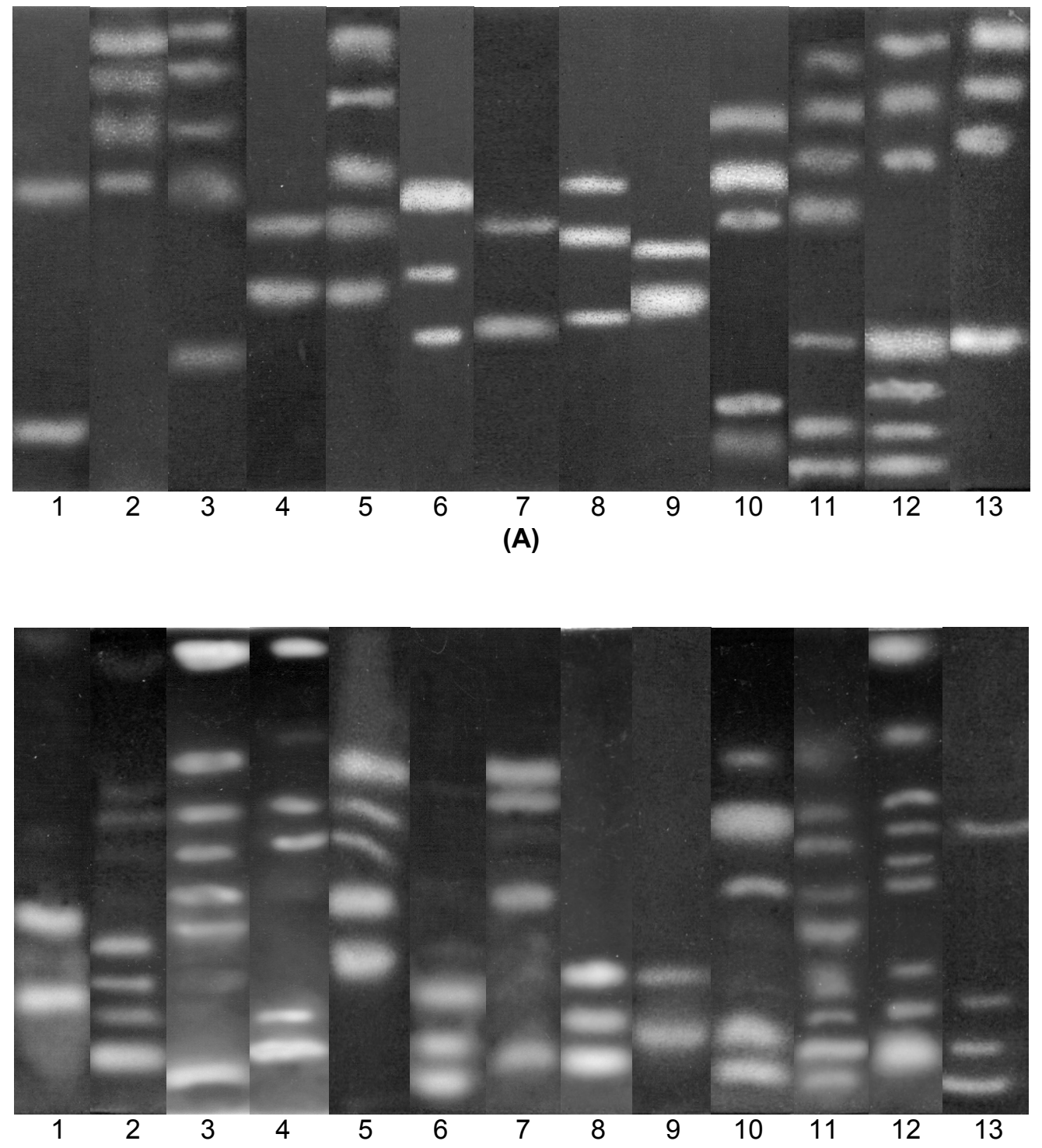

(B) 
Fig. 1. Zymogram of PAGE gel (A) and IEF gel (B) representing xylanases produced by thermophilic fungal strains: (1) Che. thermophilum, (2) Chy. lucknowense, (3) $H$. insolens, (4) $H$. fuscoatra, (5) Melanocarpus sp., (6) Malbranchea sp. (7) T. aurantiacus, and thermotolerant fungal strains: (8) Ab. corymbifera, (9) Ac. nainiana, (10) A. caespitosus, (11) A. terreus, (12) E. nidulans var. lata and (13) $P$. lagena.

Table 1. Xylanase Production by Different Thermophilic and Thermotolerant Fungal Cultures Grown on Corn Cobs and Oat Spelt Xylan under Submerged Conditions.

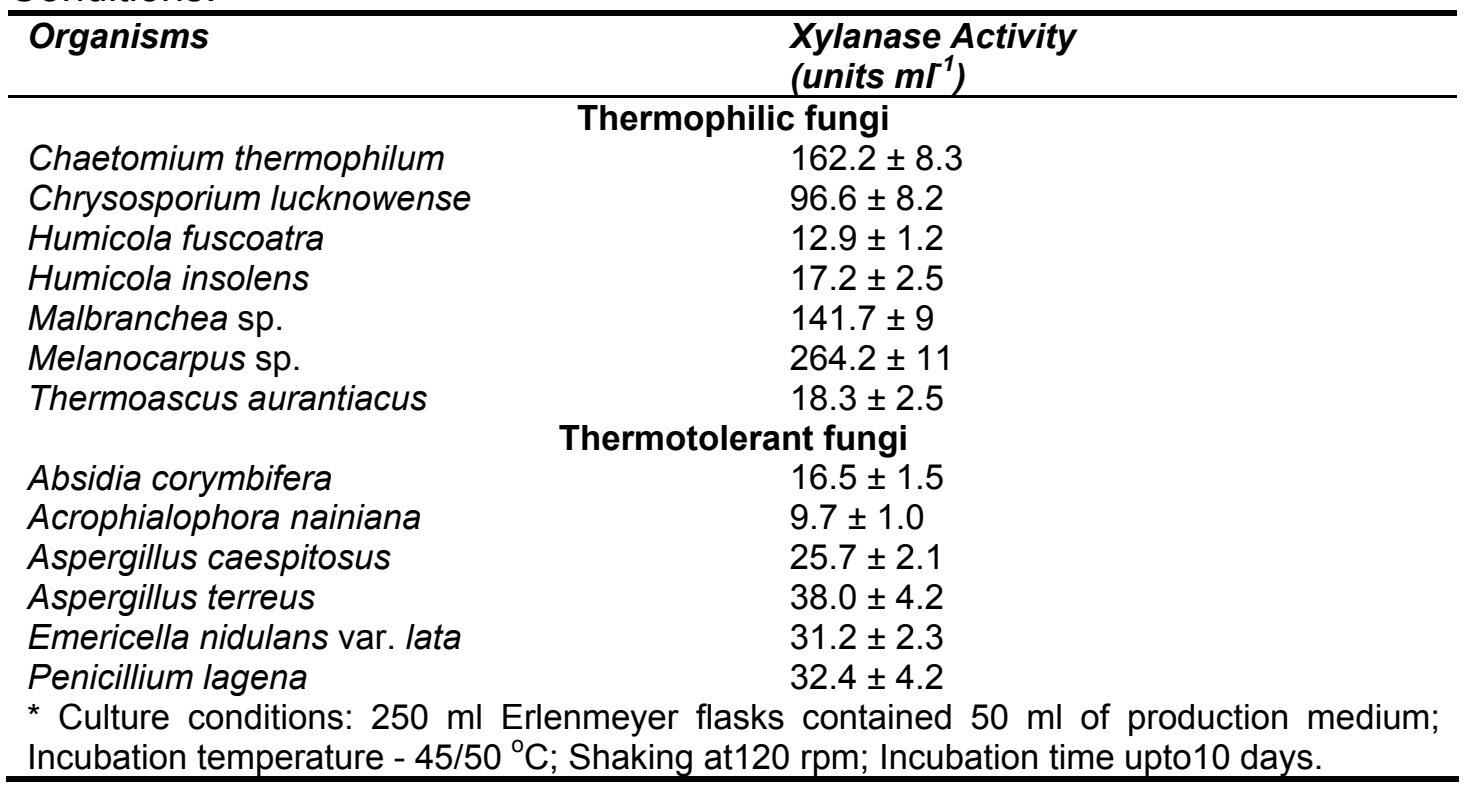

The differential expression of multiple xylanases by each strain was quantified using IEF profiling by slicing of gels and eluting proteins. By this procedure the major and minor xylanases were identified based on their relative proportions (Fig. 2.A-M). Most of the fungi produced major xylanases with neutral to acidic pI. However, $H$. fuscoatra, $H$. insolens and $E$. nidulans var. lata produced major xylanases of highly basic pI 9.7, 9.5 and 9.7 with relative proportion of $29 \%, 33 \%$ and $30 \%$, respectively (Fig. 2.L). Whereas, in Che. thermophilum, Chy. lucknowense and Malbranchea sp., xylanases of acidic $\mathrm{pI} \sim 4.5,5.5$ and 3.4, and 3.5 with high level of relative proportion i.e., $56 \%$, $31 \%, 31 \%$ and $45 \%$ were expressed, respectively (Fig. 2.A, B and E). The observed levels of minor xylanases were $2-10 \%$. Though minor xylanases are not produced in large quantities, they may be responsible for some specialized functions (induction, transglycosylation, etc.) or may work in tandem with the major xylanases to attain superior xylan hydrolysis (Wong et al. 1988; Thomson 1993).

\section{Substrate Specificity of Diverse Xylanases}

In order to demarcate the observed xylanases as catalytically distinct and novel, various xylan types were used to analyze their substrate preferences. Most of the xylanases identified highly substituted wheat arabino-xylan as the preferred substrate for hydrolysis (Table $2 \mathrm{~A}$ and $\mathrm{B}$, see Appendix). Xylanases from H. fuscoatra (HFX-VI), Ac. nainiana (ANX-VI) and E. nidulans var. lata (ENX-IV) showed 9.57, 9.71 and 8.26 fold higher activity, respectively, against wheat arabino xylan as compared to birch wood xylan (the usual substrate to assay xylanase activity). The activities of xylanases against 
rye arabino xylan, another highly substituted form of xylan, were comparable to wheat arabino xylan. Xylanases identified from H. insolens (HIX-VI), H. fuscoatra (HFX-VI), Ac. nainiana (ANX-VI) and E. nidulans var. lata (ENX-IV) were highly active against rye arabino xylan and showed 7.76, 7.51, 8.38 and 6.26 fold higher activity, respectively, as compared to birch wood xylan. However, xylanases from A. caespitosus (ACSX-II and ACSX-VII), A. terreus (ATX-I and ATX-IX) and E. nidulans var. lata (ENX-I) showed exceptionally low activity against rye arabino xylan. Few of the xylanases of $H$. fuscoatra (HFX-I), Ab. corymbifera (ACX-V and ACX-VI), A. caespitosus (ASCX-II) and E. nidulans var. lata (ENX-I) identified oat spelt xylan as the most preferred substrate.
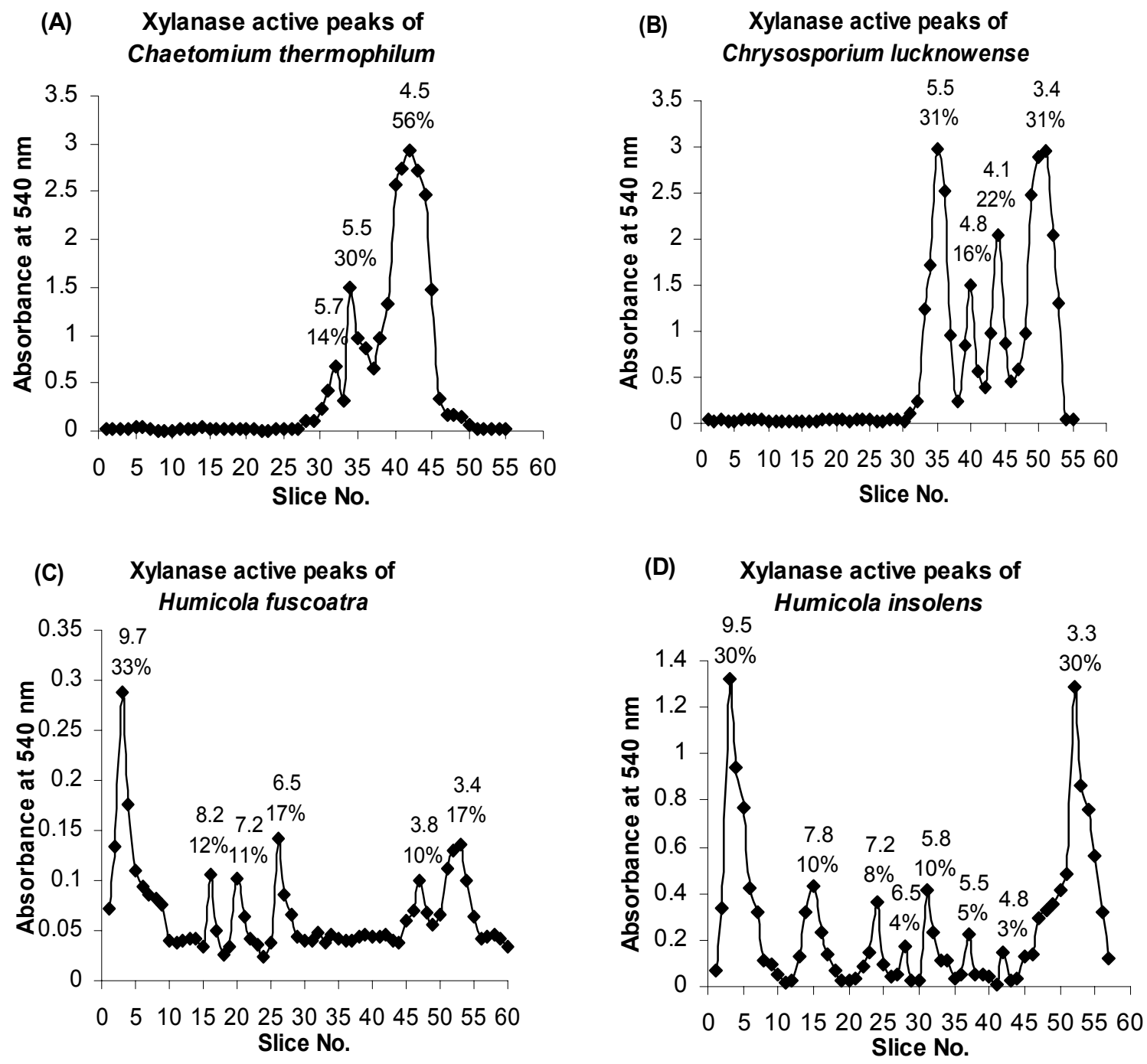

Fig. 2.A-D. Fractionation of thermophilic and thermotolerant fungi showing xylanase isoforms (pl and relative percent activity given at top of the each peak) using isoelectric focusing in polyacrylamide gel.

The activities against larch wood xylan were lower as compared to arabinoxylans, however, xylanases belonging to H. fuscoatra (HFX-II), T. aurantiacus (TAX-II), A. terreus (ATX-II) and P. lagena (PLX-I) used it as substrate of choice. The observed 
differences in the activity of xylanases on structurally and chemically distinct xylan types (Table 2 A and B) suggest that they require the presence of a particular type of substituent in the vicinity to enhance their catalytic action (Silva et al. 2000). Furthermore, endoxylanases differ in their specificity towards the xylan polymer as some enzymes cut randomly between unsubstituted xylose residues, whereas the activity of other xylanases strongly depends on the substituents (arabinosyl, arabinofuranosyl, acetyl and glucuronyl residues) linked to the xylose residues neighboring the attacked residues (de Vries and Visser 2001). Minor xylanases produced by fungal strains showed appreciably higher activities (1.5-8.2 folds) against arabino-xylans, the main constituents in the straws (rice, oat, wheat, etc.), present in the composting soils and thus may be playing a significant role in its decomposition. Few of the xylanases belonging to $A c$. nainiana, A. terreus, $P$. lagena, Chy. lucknowense and H. fuscoatra were catalytically versatile and also recognized debranched arabinan as substrate. Xylanases have cellulose binding domains with a few having the affinity to recognize xylan and cellulose (Subramanium and Prema 2002). These domains fold and function in an independent manner and may be responsible for such multi-functionality.
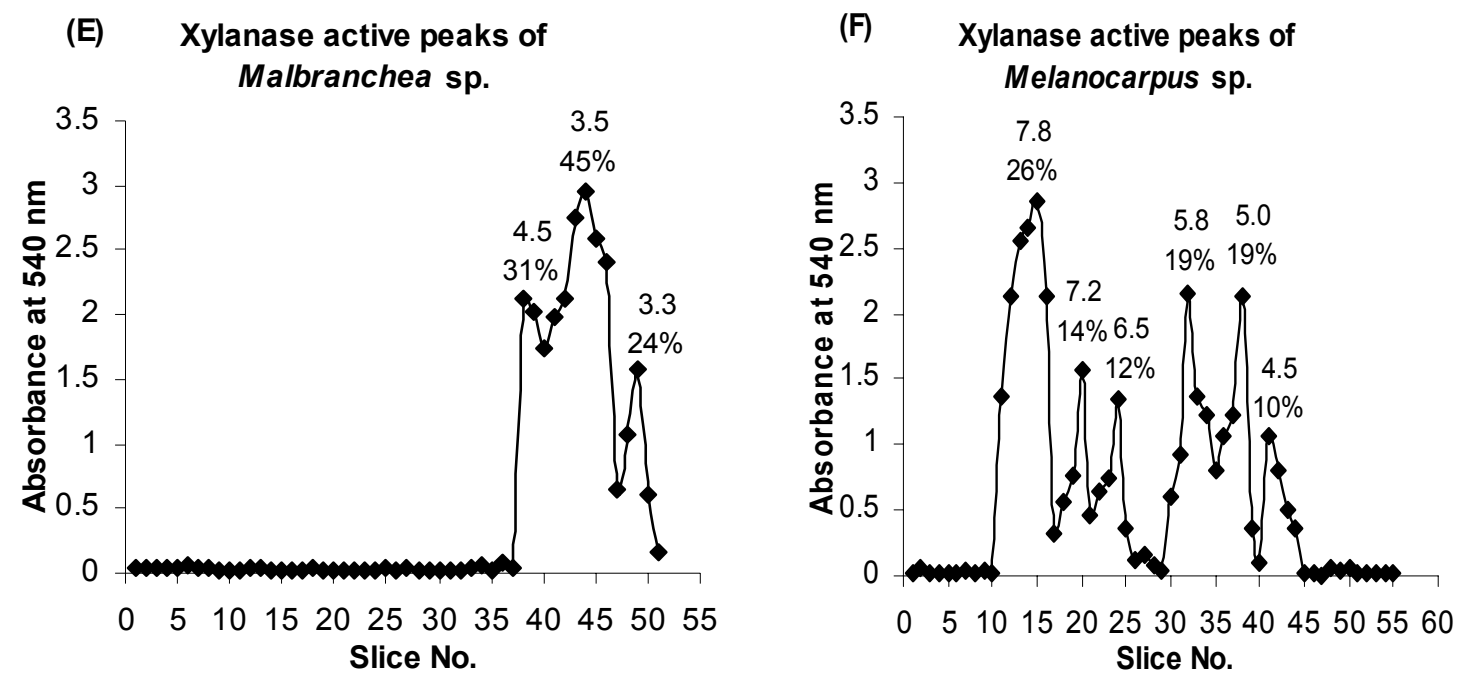

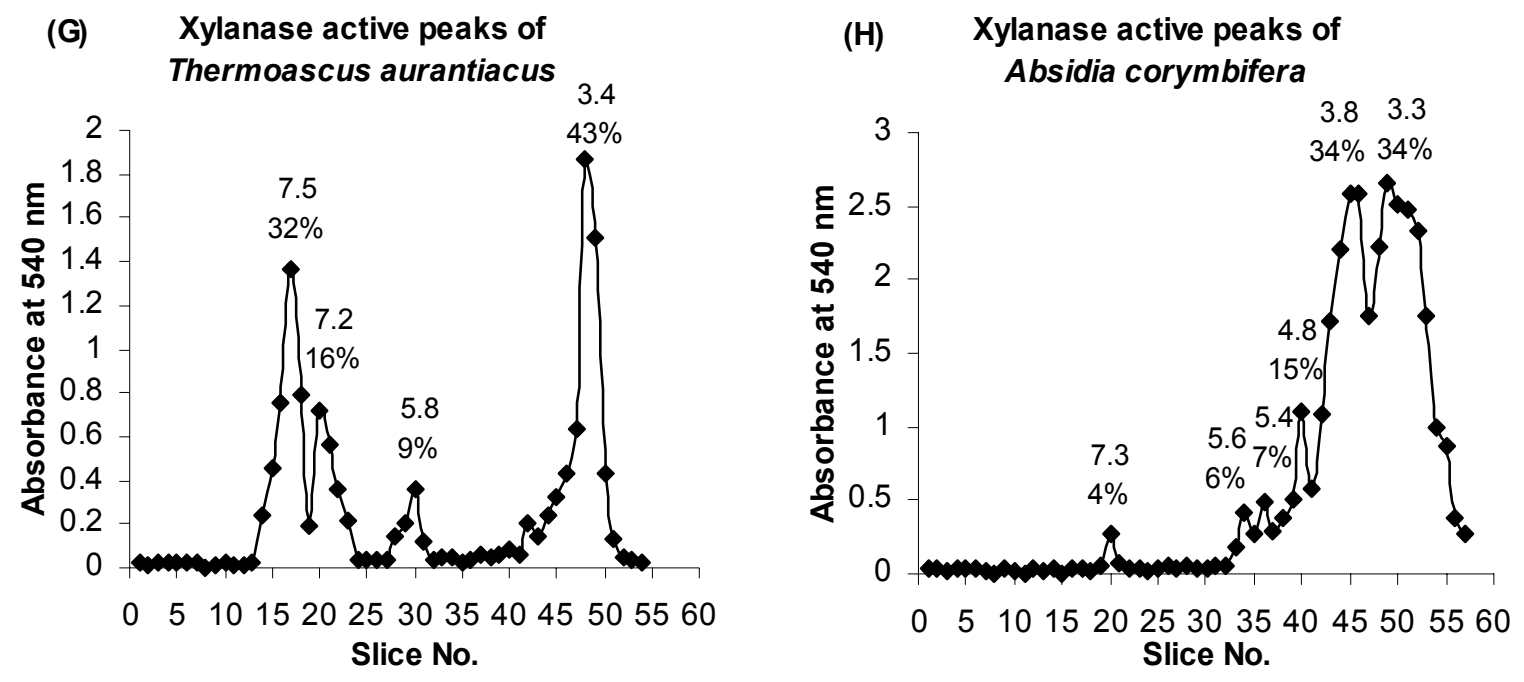

Fig. 2.E-H. Fractionation of thermophilic and thermotolerant fungi showing xylanase isoforms ( $\mathrm{pl}$ and relative percent activity given at top of the each peak) using isoelectric focusing in polyacrylamide gel.

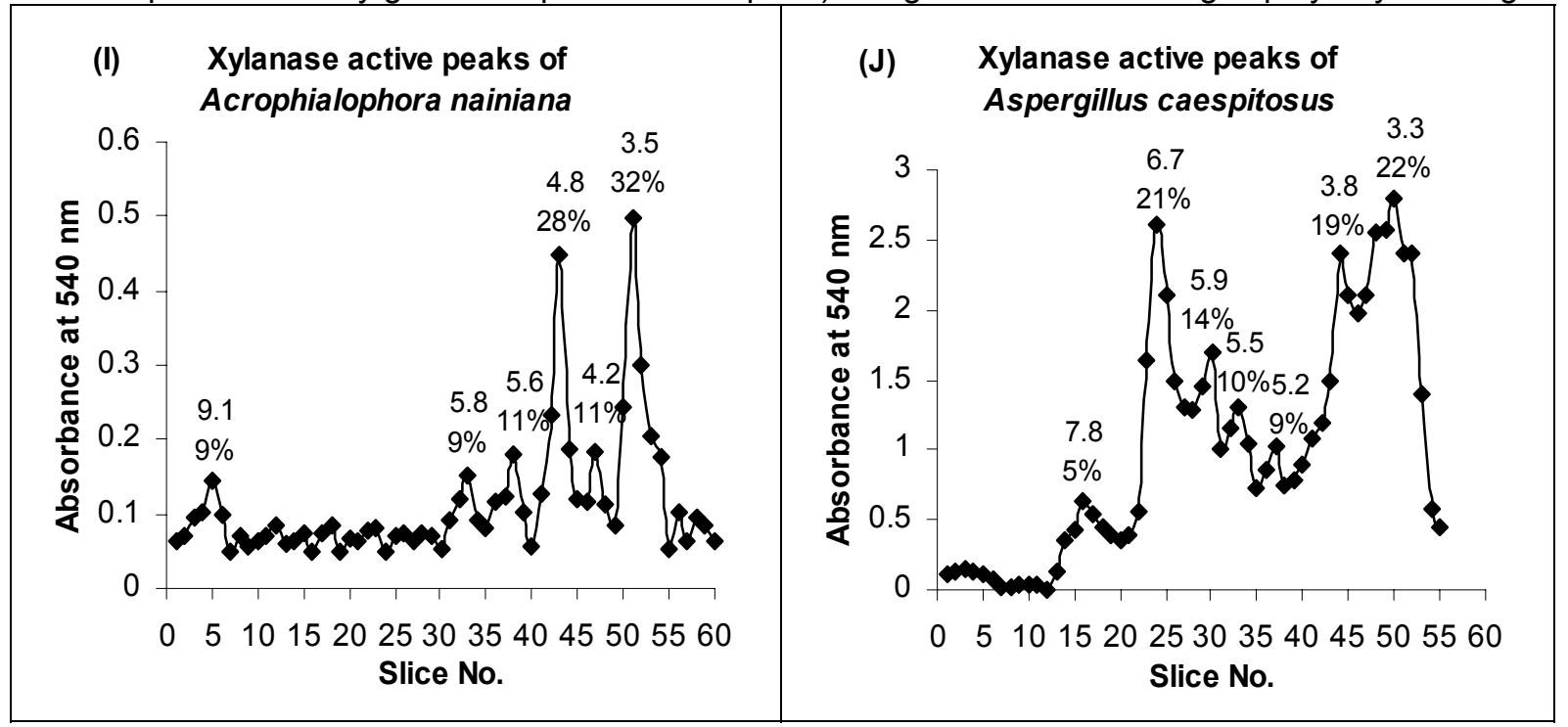




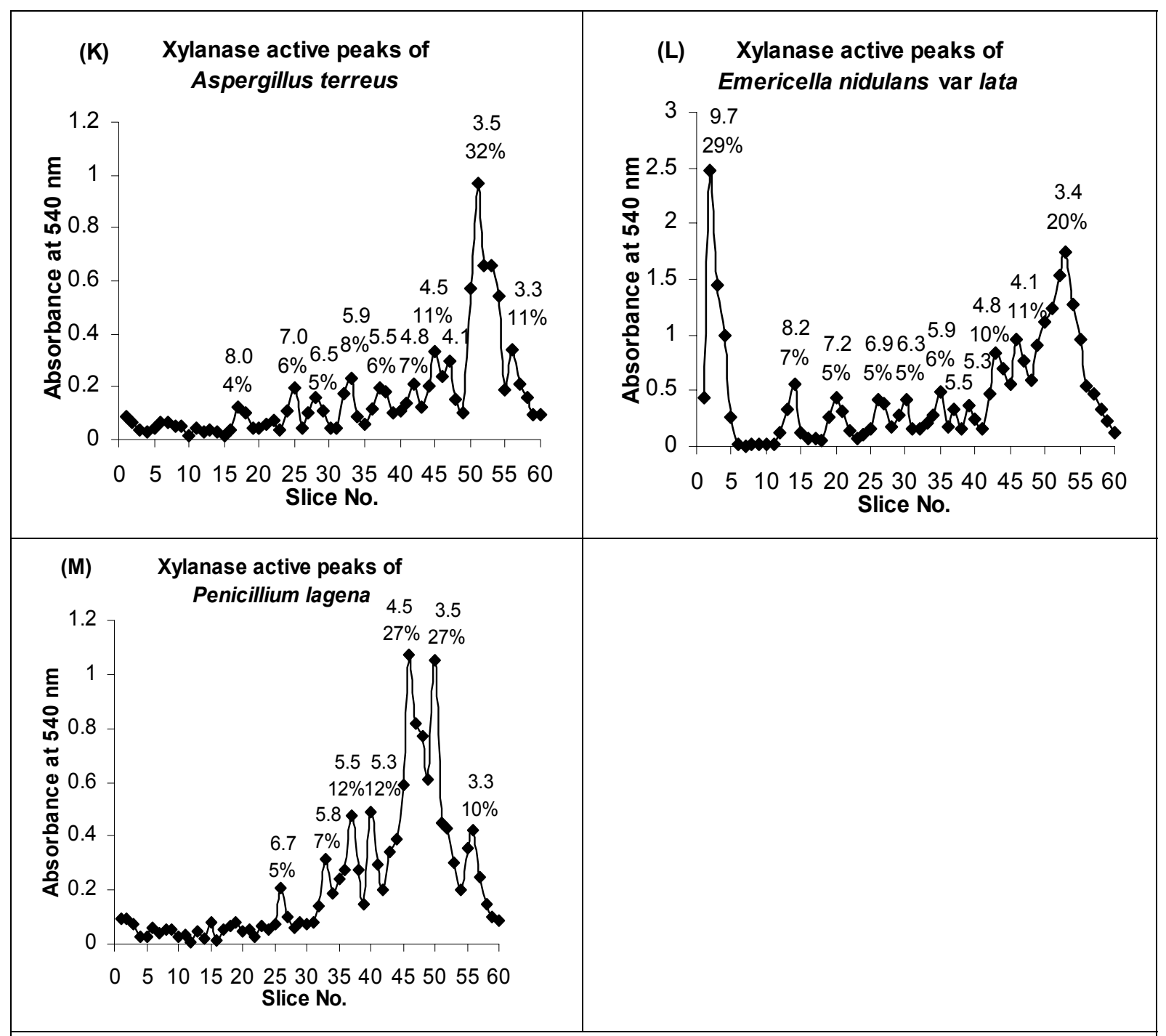

Fig. 2.I-M. Fractionation of thermophilic and thermotolerant fungi showing xylanase isoforms (pl and relative percent activity at top of the each peak) using isoelectric focusing in polyacrylamide gel.

\section{Alkaline Active Xylanases}

The alkaline active xylanases were identified on the basis of relatively higher xylanase activity against birch wood xylan at $\mathrm{pH} 9.0$ as compared to at $\mathrm{pH} 6.0$ (Table 2). Interestingly, only the xylanases of thermophilic fungal strains were found to be active under alkaline conditions. All the xylanases of Che. thermophilum, but just five of $H$. insolens and two each of $T$. aurantiacus and Malbranchea sp. were active under alkaline conditions. Of the six isoforms produced by Melanocarpus sp., only one xylanase isoform (MAX-I) was active at alkaline $\mathrm{pH}$. There are evidences to suggest that geographically distinct strains produce xylanases of different physicochemical characters as Che. cellulolyticum isolated in Pushchino, Russia, produced three xylanases with $\mathrm{pI}$, 8.9, 8.4 and 5.0 that were active at neutral $\mathrm{pH}$ (Baraznenok et al. 1999), while we observed the expression of three alkaline active xylanases of acidic pI, 5.7, 5.5 and 4.5 by Che. thermophilum. 
Table 3. Effect of Xylanase (Xylanase of Diverse Thermophilic and Thermotolerant Fungi) Pretreatment on the Release of Chromophoric Material and Reducing Sugars from Pulp, and Brightness of Pulp.

\begin{tabular}{|c|c|c|c|c|c|c|}
\hline Organisms & \multicolumn{4}{|c|}{$\begin{array}{l}\text { Chromophore release } \\
237 \mathrm{~nm} 254 \mathrm{~nm} 280 \mathrm{~nm} 465 \mathrm{~nm}\end{array}$} & \multirow[t]{2}{*}{$\begin{array}{l}\text { Reducing Sugar } \\
\text { (mg g } \text { g }^{-1} \text { Pulp) }\end{array}$} & \multirow[t]{2}{*}{$\begin{array}{l}\text { Brightness } \\
\text { (\% ISO) }\end{array}$} \\
\hline \multicolumn{5}{|c|}{ Thermophilic fungi } & & \\
\hline Control & 0 & 0 & 0 & 0 & 0 & $32.40 \pm 0.20$ \\
\hline Che. thermophilum & 0.604 & 0.497 & 0.408 & 0.083 & 0.379 & $34.01 \pm 0.10$ \\
\hline Chy. lucknowense & 0.835 & 0.587 & 0.543 & 0.163 & 0.339 & $34.03 \pm 0.10$ \\
\hline H. fuscoatra & 0.534 & 0.510 & 0.545 & 0.099 & 0.171 & $34.00 \pm 0.10$ \\
\hline H. insolens & 0.546 & 0.536 & 0.524 & 0.173 & 0.209 & $34.04 \pm 0.10$ \\
\hline Malbranchea sp. & 1.827 & 1.701 & 0.857 & 0.120 & 0.399 & $34.44 \pm 0.15$ \\
\hline Melanocarpus sp. & 0.906 & 0.197 & 0.136 & 0.043 & 0.389 & $34.21 \pm 0.10$ \\
\hline T. aurantiacus & 0.745 & 0.359 & 0.366 & 0.093 & 0.018 & $34.02 \pm 0.10$ \\
\hline \multicolumn{7}{|c|}{ Thermotolerant fungi } \\
\hline Ab. corymbifera & 0.123 & 0.095 & 0.065 & 0.046 & 0.098 & $32.48 \pm 0.12$ \\
\hline Ac. nainiana & 0.211 & 0.102 & 0.098 & 0.035 & 0.121 & $33.81 \pm 0.10$ \\
\hline A. caespitosus & 0.809 & 0.717 & 0.521 & 0.110 & 0.298 & $34.10 \pm 0.10$ \\
\hline A. terreus & 0.289 & 0.156 & 0.110 & 0.065 & 0.235 & $33.07 \pm 0.10$ \\
\hline E. nidulans var. lata & 0.221 & 0.142 & 0.118 & 0.061 & 0.169 & $33.95 \pm 0.10$ \\
\hline$P$. lagena & 0.245 & 0.152 & 0.121 & 0.055 & 0.175 & $33.78 \pm 0.10$ \\
\hline
\end{tabular}

\section{Enzymatic Treatment of Pulp}

Xylanase produced by thermophilic and thermotolerant fungal strains was used for the bleaching of Decker pulp. Interestingly, xylanases from all the thermophilic fungi showed a bleach boosting effect on the pulp, however, among thermotolerant fungi, only A. caespitosus xylanase was found to be effective. These biobleaching studies revealed that maximal chromophore release, reducing sugar release and brightness of pulp, was observed with alkaline active xylanases from novel strain of Malbranchea sp., with a gain of 2.04 ISO units (Table 3), and was much better as compared to other sources of alkaline active xylanases (1.63-1.81 ISO units) identified in this study. The observed increase in the pulp brightness by 2.04 units may result in decreased chlorine consumption by $20-25 \%$ as observed previously with commercial xylanases Novozyme 473 and VAI-Xylanase (Bajpai et al. 1994).

\section{CONCLUSIONS}

This paper highlights the use of simple techniques like PAGE and IEF for high through-put screening of diverse xylanases from different fungal cultures. Furthermore, the techniques can also be used for identification of xylanases with novel properties.

\section{ACKNOWLEDGEMENTS}

Financial support provided by Department of Biotechnology, New Delhi (India) for carrying out this study is duly acknowledged. 


\section{REFERENCES}

Badhan, A. K., Chadha, B. S., Ghatora, S. K., Saini, H. S., and Bhat, M. K. (2004). "Functionally diverse multiple xylanases of thermophilic fungus Myceliophthora sp. IMI 387099," Enzyme Microb. Technol. 35, 460-466.

Badhan, A. K., Chadha, B. S., Jatinder, K., Saini, H. S., and Bhat, M. K. (2006). "Production of multiple xylanolytic and cellulolytic enzymes by thermophilic fungus Myceliophthora sp. IMI 387099," Bioresource Technol. (In press).

Bajpai, P., Bhardwaj, N. K., and Bajpai, P. K. (1994). "The impact of xylanases on bleaching of eucalyptus Kraft pulp," J. Biotechnol. 38, 1-6.

Baraznenok, V. A., Becker, V. A., Ankudimova, N. V., and Okanev, N. N. (1999). "Characterization of neutral xylanases from Chaetomium cellulolyticum and their biobleaching effect on eucalyptus pulp," Enzyme. Microb. Technol. 25, 651-659.

Bhat, M. K., and Wood, T. M. (1989). "Multiple forms of endo-1,4- $\beta$-D-Glucanase in the extracellular cellulase of Pencillium pinophilum" Biotechnol. Bioeng. 33, 1242-1248.

Collins T., Gerday, C., and Feller, G. (2005). "Xylanases, xylanase families and extremophilic xylanases," FEMS Microbiol. Rev. 29, 3-23.

Cooney, D. C., and Emerson, R. (1964). Thermophilic fungi: An Account of Their Biology, Activities and Classification. San Francisco: W.H. Freeman \& Co.

De Vries, R. P., and Visser, J. (2001). "Aspergillus enzymes involved in degradation of plant cell wall polysaccharides," Microbiol. Mol. Biol. Rev. 65, 497-522.

Eneyaskaya, E. V., Brumer III, H., Backinovsky, L.V., Ivanen, D. R., Kulminskaya, A. A., Shabalin, K. A., and Neustroev, K. N. (2003). "Enzymatic synthesis of $\beta$-xylanase substrates: transglycosylation reactions of the $\beta$-xylosidase from Aspergillus sp," Carbohydr. Res. 338, 313-325.

Gomez De Segura, B., Durand, R., and Févre, M. (1998). "Multiplicity and expression of xylanases in the rumen fungus Neocallimastix frontalis," FEMS Microbiol. Lett. 164, 47-53.

Kormelink, F. J. M., and Voragen, A.G. J. (1993). "Degradation of different [(glucurono) arabino] xylans by combination of purified xylan degrading enzymes," Appl. Microbiol. Biotechnol. 38, 688-695.

Laemmli, U. K. (1970). "Cleavage of structural proteins during the assembly of the head of bacteriophage-T4," Nature 227, 680-685.

Li, K., Azadi, P., Collins, R., Tolan, J., Kim, J. S., and Eriksson K. L. (2000). "Relationships between activities of xylanases and xylan structures," Enzyme Microb. Technol. 27, 89-94.

Maheshwari, R., Bhardwaj, G., and Bhat, M. K. (2000). "Thermophilic fungi: Their physiology and enzymes," Microbiol. Mol. Biol. Rev. 63, 461-488.

Sachslehner, A., Nidetzky, B., Kulbe, D. K., and Haltrich D. (1998). "Induction of mannanase, xylanase and endoglucanase activities in Sclerotium rolfsii" Appl. Environ. Microbiol. 64, 594-600.

Saha, B. C. (2003). "Hemicellulose bioconversion," J Ind. Microbiol. Biotechnol. 30, 279-291.

Saraswat, V., and Bisaria, V. S. (2000). "Purification, characterization and substrate specificities of xylanase isozymes from Melanocarpus albomyces IIS 68," Biosci. Biotechnol. Biochem. 64, 1173-1180. 
Shallom, D., and Shoham, Y. (2003). Microbial hemicellulases. Curr. Opin. Microbiol. 6, 219-228.

Sharma, H. S. K. (1989). "Economic importance of thermophilous fungus," Appl. Microbiol. Biotechnol. 31, 1-10.

Silva, C. H. C., Fonsêca, A. S., Lucena-Neto, S. A., Ximenes, E. A., Puls, J., and Filho, E. X. F. (2000). "Evaluation of hydrolysis products of xylan degrading enzymes from Humicola grisea var. thermoidea and Aspergillus fumigatus Fresenius," World J. Microbiol. Biotechnol. 16, 81-83.

Subramanium, S., and Prema, P. (2002). "Biotechnology of microbial xylanases: Enzymology, molecular biology and application," Critical Rev. Biotechnol. 22, 3346.

Sunna, A. and Berguist, P. L. (2003). "A gene encoding a novel extremely thermostable $1,4-\beta$-xylanase isolated directly from an environmental DNA sample," Extremophiles 7, 63-70.

Thomson, J. A. (1993). "Molecular biology of xylan degradation," FEMS Microbiol. Rev. $104,65-82$.

Uffen, R. L. (1997). "Xylan degradation: a glimpse at microbial diversity," $J$ Ind. Microbiol. Biotechnol. 19, 1-6.

Viikari, L., Kantelinen, A., Buchert, J., and Puls, J. (1994). "Enzymatic accessibility of xylans in lignocellulosic materials," Appl. Microbiol. Biotechnol. 41, 124-129.

Wong, K. K. Y., Tan, L. U. L., and Saddler, J. N. (1988). "Multiplicity of $\beta$-1,4-xylanase in microorganisms: function and applications," Microbiol. Rev. 52, 305-317. 
Table 2B. The Relative Percent Activities of Xylanase Isoforms (Peak Fractions) of Different Thermotolerant Fungi against Different Types of Xylan Substrates (Substituted and Unsubstituted) and Debranched Arabinan.

\begin{tabular}{|c|c|c|c|c|c|c|c|}
\hline $\begin{array}{l}\text { Substrate }^{a} \rightarrow \\
\text { Isoforms }\end{array}$ & $B W X^{b}$ & $L W X^{b}$ & OSX & $R A X^{6}$ & WAX & $D A^{b}$ & $B W X^{c}$ \\
\hline \multicolumn{8}{|c|}{ Thermotolerant fungi } \\
\hline \multicolumn{8}{|c|}{ Absidia corymbifera } \\
\hline ACX-I (7.3) & 100 & 185 & 110 & 352 & 428 & - & 83 \\
\hline ACX-II (5.6) & 100 & 216 & 110 & 462 & 529 & - & 52 \\
\hline ACX-III (5.4) & 100 & 123 & 103 & 247 & 303 & - & 88 \\
\hline ACX-IV (4.8) & 100 & 108 & 171 & 165 & 281 & - & 79 \\
\hline$A C X-V(3.8)$ & 100 & 101 & 175 & 147 & 156 & - & 84 \\
\hline ACX-VI (3.3) & 100 & 105 & 180 & 112 & 137 & - & 89 \\
\hline \multicolumn{8}{|c|}{ Acrophialophora nainiana } \\
\hline ANX-I (9.1) & 100 & 200 & 171 & 557 & 666 & 66 & 7 \\
\hline ANX-II (5.8) & 100 & 152 & 184 & 456 & 604 & 72 & 14 \\
\hline ANX-III (5.6) & 100 & 215 & 162 & 587 & 575 & 34 & 62 \\
\hline ANX-IV (4.8) & 100 & 278 & 232 & 450 & 685 & 60 & 55 \\
\hline ANX-V (4.2) & 100 & 208 & 174 & 448 & 756 & 32 & 46 \\
\hline ANX-VI (3.5) & 100 & 322 & 466 & 838 & 971 & 66 & 41 \\
\hline \multicolumn{8}{|c|}{ Aspergillus caespitosus } \\
\hline ASCX-I (7.8) & 100 & 107 & 109 & 108 & 158 & - & 25 \\
\hline ASCX-II (6.7) & 100 & 94 & 142 & 67 & 100 & - & $90 * *$ \\
\hline ASCX-III (5.9) & 100 & 75 & 70 & 101 & 135 & - & 32 \\
\hline ASCX-IV (5.5) & 100 & 128 & 148 & 175 & 244 & - & 38 \\
\hline ASCX-V (5.2) & 100 & 131 & 93 & 216 & 232 & - & 71 \\
\hline ASCX-VI (3.8) & 100 & 104 & 120 & 162 & 214 & - & $98^{* *}$ \\
\hline ASCX-VII (3.3) & 100 & 94 & 102 & 99 & 131 & - & $96^{* *}$ \\
\hline \multicolumn{8}{|c|}{ Aspergillus terreus } \\
\hline ATX-I (8.0) & 100 & 278 & 87 & 70 & 274 & 34 & 22 \\
\hline ATX-II (7.0) & 100 & 403 & 150 & 146 & 300 & 53 & 7 \\
\hline ATX-III (6.5) & 100 & 246 & 135 & 203 & 417 & 61 & 25 \\
\hline ATX-IV (5.9) & 100 & 294 & 102 & 205 & 405 & 47 & 2 \\
\hline ATX-V (5.5) & 100 & 212 & 201 & 398 & 306 & 30 & 17 \\
\hline ATX-VI (4.8) & 100 & 277 & 120 & 283 & 368 & 18 & 21 \\
\hline ATX-VII (4.5) & 100 & 185 & 99 & 179 & 273 & - & 17 \\
\hline ATX-VIII (4.1) & 100 & 88 & 89 & 150 & 260 & - & 20 \\
\hline ATX-IX (3.5) & 100 & 75 & 130 & 76 & 252 & - & 7 \\
\hline ATX-X (3.3) & 100 & 226 & 96 & 234 & 321 & - & 13 \\
\hline \multicolumn{8}{|c|}{ Emericella nidulans var. lata } \\
\hline ENX-I (9.7) & 100 & 94 & 130 & 47 & 79 & - & 3 \\
\hline ENX-II (8.2) & 100 & 134 & 123 & 125 & 156 & - & 36 \\
\hline ENX-III (7.2) & 100 & 175 & 118 & 330 & 307 & - & 66 \\
\hline ENX-IV (6.9) & 100 & 393 & 120 & 626 & 826 & - & 76 \\
\hline ENX-V (6.3) & 100 & 226 & 140 & 463 & 200 & - & 66 \\
\hline ENX-VI (5.9) & 100 & 163 & 103 & 343 & 350 & - & 70 \\
\hline ENX-VII (5.5) & 100 & 179 & 63 & 401 & 384 & - & 68 \\
\hline ENX-VIII (5.3) & 100 & 125 & - & 241 & 410 & - & 71 \\
\hline ENX-IX (4.8) & 100 & 104 & 150 & 187 & 194 & - & 80 \\
\hline ENX-X (4.1) & 100 & 134 & 153 & 219 & 293 & - & 58 \\
\hline ENX-XI (3.4) & 100 & 96 & 145 & 173 & 211 & - & 44 \\
\hline \multicolumn{8}{|c|}{ Penicillium lagena } \\
\hline PLX-I (6.7) & 100 & 227 & 177 & 211 & 188 & - & 18 \\
\hline PLX-II (5.8) & 100 & 307 & 115 & 456 & 433 & 28 & 26 \\
\hline
\end{tabular}


